\title{
A test of Luce's two-state decision rule
}

WAYNE A. WICKELGREN

MASSACHUSETTS INSTITUTE OF TECHNOLOGY

Luce's (1963) two-state decision rule was tested and confirmed. The task required a choice between two alternatives, one of which was recommended by a partially accurate observer whose accuracy was known only within rather broad limits (60-90\%). The bias to choose one alternative or the other was manipulated by payoff matrices.

Imagine that you are to make a "yes-no" (y-n) decision about whether stimulus $\mathrm{Y}$ or stimulus $\mathrm{N}$ was "presented" on that trial. The only information you have about the presence of $\mathrm{Y}$ or $\mathrm{N}$ is the binary ( 1 or 0) report of a partially accurate (60-90\%) "perceiver" (1 goes with $Y$ goes with $y$ ). Payoffs for correct and incorrect decisions of both types are specified on each trial by a 2 by 2 payoff matrix. If, on some trial, your partially accurate perceiver reports "1"' and the payoff is symmetric (correct decisions gain you one point, incorrect decisions cost you one point), what will you decide? To almost everyone the question seems so trivial that they are sure it must be a trick. Obviously one should choose $y$ and, if one did not think there was any possibility of a trick, intuition assures us that almost every human being would choose $\mathrm{y}$.

Of course, it is possible to make the situation a little more interesting by making the payoffs asymmetric, for example, paying 6 for a correct $n$ decision and charging only 1 for an incorrect $n$ decision, while paying only 1 for a correct $y$ decision and charging 6 for an incorrect $y$ decision. Now what do you choose, if the perceiver says "1"? Given the vague information one has about the accuracy of the perceiver, there is no obviously right answer to this question, and the probability of a subject's choosing $y$ in this situation could be anything between 0 and 1 . However, with this payoff matrix, if the perceiver says " $0, "$ it is obvious that one should choose $n$, and again our intuition tells us that almost every human being would choose $n$.

In essence, the above two paragraphs have specified Luce's (1963) two-state decision rule. A formal statement of the rule can be found in Luce (1963). A simple intuitive statement of the rule is as follows: Whenever the payoff matrix does not "go against" the perceiver, always follow the perceiver. Note that a symmetric payoff matrix does not go against either kind of report; asymmetric payoffs go against one of the two possible reports.

The present paper reports an experimental test of Luce's two-state decision rule. One reason for testing the rule is that its validity is crucial for the evaluation by means of operating characteristics of the hypothesis that some particular sensory or memory system in human beings has only two states. For a discussion of this issue, see Wickelgren (in press).

\section{Method}

The only cases that are important for testing Luce's rule are those where the payoff matrix does not go against the percelver. However, there is a danger that these cases might seem too obvious to many Ss, leading them to misperceive the task or "fool around." To prevent this, some more interesting cases where the payoff matrix went against the perceiver were intermixed with the "gymmetric" and "went with" cases. In some of the "went against" cases, it was possible to determine which choice would produce the maximum expected value (no matter what the accuracy of the perceiver in the range from 60 to $90 \%$ ). In other cases, this was not possible. Thirteen different payoff matrices were used, six favoring "yes" answers, one symmetric, and six favoring "no" answers. See Table 1 for a list of the six types of asymmetric matrices. There were 26 different conditions, representing all combinations of the two perceiver reports with the 13 payoff matrices. A conditions was presented on a $3 \times 5$ card as follows:

Semiaccurate Perceiver says YES $(60-90 \%)$

\begin{tabular}{|c|c|c|c|}
\hline & & \multicolumn{2}{|c|}{ RESPOND } \\
\hline & & YES & $\mathrm{NO}$ \\
\hline & YES & +1 & -1 \\
\hline & NO & -6 & +6 \\
\hline
\end{tabular}

Five sec was allowed for responding to a given card. All 26 conditions were presented, then the pack was shuffled and presented again. In a single session, the 26 conditions were presented 23 times. There were four sessions for each $\mathrm{S}$.

Five M.I.T. students were run, two under the perceptual set previously described, and three under a recognition memory instructional set. The recognition memory set was formally identical to the perceptual set, except that the information was said to be provided by a partially accurate external memory. All Ss were paid, but their pay was not contingent upon their performance. Luce's two-state decision rule should be correct without financial motivation, for intellectualachievement motivation would appear to be stronger than the small financial motivation that can be offered in experiments of this sort.

There was no trial to trial feedback. That is, Ss were not told, after they had chosen $y$ or $n$, whether $Y$ or $N$ had been presented on that trial. Feedback can produce sequential dependencies on the prior outcome sequence even in a psychophysical task (Carterette, Friedman, \& Wyman, 1966). Its effect on a decision making experiment of the present type can be to turn it into a binary prediction task with Ss focusing largely or exclusively 
Table 1 Percentage of choices that "agreed with" the partially accurate perceiver or memorizer (PM)

\begin{tabular}{llcccc}
\hline Payoff Matrix & \multicolumn{3}{c}{ Memory Set } & \multicolumn{3}{c}{ Perceptual Set } \\
& MG & DB & SB & SP & CH \\
"went with PM" & 1.00 & 1.00 & .99 & 1.00 & 1.00 \\
symmetric & 1.00 & 1.00 & 1.00 & .99 & 1.00 \\
"went against PM" & & & & & \\
$1,-1$ vs $-2,2$ & 1.00 & .98 & .86 & .90 & .90 \\
$1,-1$ vs $-3,3$ & .99 & .98 & .90 & .72 & .76 \\
$1,-1$ vs $-4,4$ & .10 & .00 & .98 & .10 & .01 \\
$1,-1$ vs $-6,6$ & .04 & .00 & .98 & .07 & .00 \\
$1,-1$ vs $-8,8$ & .04 & .00 & .38 & .06 & .01 \\
$1,-1$ vs $-10,10$ & .02 & .00 & .38 & .04 & .02 \\
\hline
\end{tabular}

on the prior sequence of outcomes. The experiments of Lee (1963), Lee \& Janke $(1964,1965)$, Lee \& Zentrall (1966), and Lee \& Gordon (1966), which attempted to test the criterion decision rule of signal detection theory seem particularly likely to lead to a sequential "patterm guessing" set, and the results of these experiments suggest this did in fact occur. If this is true, these experiments are inconclusive with respect to the decision rule used by humans in unidimensional decision making on a continuous scale.

Results and Discussion

The probabilities of choices that agreed with the partially accurate perceiver or memorizer (PM) when the payoff matrix: (a) went with the PM, (b) was symmetric, or (c) went against the PM are shown in Table 1. The went with results are averaged over all payoff matrices because the differences were negligible.

The probabilities for the went with and symmetric payoff matrices are the only ones that test Luce's two-state decision rule. These probabilities are predicted to be 1.00 by Luce's rule, and the empirical probabilities are 1.00 or .99 for every $S$. Thus, the results indicate that Luce's two-state decision rule is correct, in accord with intulition. The occasional violations were so rare that they can be ignored for the purposes of testing two-state theories of perception and memory by means of operating characteristics. Furthermore, the few violations that did occur were confined almost entirely to the first session and seem attributable to the conceptual complexity introduced by shifting the payoff matrix on every trial and giving the $S$ only 5 sec to respond.
That the results were so highly consistent with Luce's "rational" decision rule for dichotomous information, even when Ss had to rapidly adjust to a new payoff matrix on every trial, argues strongly for its general validity. Certainly, there is no reason to suggest that rapid switching of payoff matrices induces Ss to use the rational decision rule. Nevertheless, if one is concerned about this, one could always test the two-state assumption about the sensory or memory system under comparable conditions (with the payoff matrix switched on every trial).

The results of the present experiment support Luce's two-state decision rule and suggest that, wherever continuous operating characteristics are found by varying payoff matrices, we can be rather confident that the sensory or memory system has more than two states. Of course, to be absolutely sure of this, future experiments to test the two-state hypothesis in some sensory or memory absolute judgment situation, might replicate the present decision making experiment on the same Ss that perform in the sensory or memory task-just to be sure that Luce's rule is true for these Ss.

\section{References}

CARTERETTE, E. C., FRIEDMAN, M. P., \& WYMAN, M. J. Feedback and psychophysical variables in signal detection.J. Acoust. Soc. Amer., $1966,39,1051-1055$.

LEE, W. Choosing among confusably distributed stimuli with specified likelihood ratios. Percept. mot. Skills, 1963, 16, 445-467.

LEE, W., \& GORDON, M. E. Paired-comparisons choice for externally distributed stimuli. Canad. J. Psychol, 1966, 20, 352-361.

LEE, W., \& JANKE, MARY. Categorizing externally distributed stimulus samples for three continua. J. exp. Psychol., 1964, 68, 376-382.

LEE, W., \& JANKE, MARY. Categorizing externally distributed stimulus sampies for unequal molar probabilities. Psychol Rep., 1965, 17, 79 90.

LEE, W., \& ZENTALL, T. R. Factorial effects in the categorization of externally distributed stimulus samples. Percept. \& Psychophys, 1966, $1,120-124$.

LUCE, R. D. A threshold theory for simple detection experiments. Psychol Rev., 1963, 70, 61-79.

WICKELGREN, W. A. Testing two-state theories with operating characteristics and a posteriori probabilities. Psychol Bulh, in press.

Note

1. This work was supported primarily by grant MH $08890-03$ from the National Institute of Mental Health, U. S. Public Health Service. Further aid was received from a National Aeronautics and Space Administration grant NsG 496 to Hans-Lukas Teuber. 